\title{
Adsorção e deslocamento do íon cádmio em solos do cerrado
}

\author{
Luiz F. C. Oliveira ${ }^{1}$, Mara L. Lemke-de-Castro², Cristiane Rodrigues² \& Jácomo D. Borges ${ }^{2}$
}

\begin{abstract}
RESU MO
Comumente, o cádmio é encontrado em resíduos industriais e urbanos, lodo de esgoto e fertilizantes que, quando dispostos no solo, podem representar riscos de poluição do solo e água. Propôs-se, neste trabalho, analisar a adsorção e o deslocamento do ín cádmio nos Latossolo Vermelho Acriférrico, Argissolo Vermelho Eutrófico, Nitossolo Vermelho Eutroférrico e Neossolo Q uartzarênico, encontrados em áreas de cultivo do Estado de Goiás. Para a determinação da quantidade de cádmio adsorvido, $50 \mathrm{~mL}$ de soluç̧ão de $\mathrm{CaCl}_{2} 2 \mathrm{H}_{2} \mathrm{O}\left(0,01 \mathrm{~mol} \mathrm{~L}^{-1}\right)$ com diferentes concentrações de $\mathrm{Cd}$ $\left(0,10 ; 1,80 ; 19,00 ; 46,60\right.$ e 105,70 $\left.\mathrm{mg} \mathrm{L}^{-1}\right)$ foram adicionados a 5,0 mL de terra fina secada em estufa e agitados $24 \mathrm{~h}$; cuja sorção foi avaliada pelos modelos potencias e lineares da isoterma Freundlich. No ensaio do transporte utilizou-se uma deslocadora de $\mathrm{Cd}$, em colunas de solo, na concentração de $105,70 \mathrm{mg} \mathrm{L}^{-1}$, em que os fatores de retardamento (R) e coeficientes de dispersão hidrodinâmica (D), foram ajustados pela minimização da soma dos quadrados dos desvios entre as curvas de eluição experimental e simulada. Tanto as isotermas lineares e potenciais como os parâmetros de transporte $\mathrm{R}$ e $\mathrm{D}$ apresentaram bom ajuste para descrever a adsorção e o deslocamento do $\mathrm{Cd}$ nas diferentes classes de solo estudadas. 0 Neossolo apresentou retenção menor do Cd em comparação com as demais classes de solo sendo, portanto, mais vulnerável à contaminação das águas subterrâneas, seguido do Latossolo, A rgissolo e Nitossolo.
\end{abstract}

Palavras-chave: isoterma de sorção, fator de retardamento, deslocamento miscível, dispersão hidrodinâmica

\section{Adsorption and displacement of the cadmium ion in savannah soils}

\begin{abstract}
Cadmium is commonly found in industrial and urban residues, sewer sludge and fertilizers, and when disposed in the soil can represent risks of pollution of the soil and water. This study aimed to analyze the adsorption and movement of cadmium in Red Latosol, Red Argisol, Red Nitosol and Quartzarenic Neosol found in cultivated áreas in the State of Goiás. In order to quantify the adsorbed cadmium, $5 \mathrm{~mL}$ of oven-dried soil were stirred in beaker, for $24 \mathrm{~h}$, with $50 \mathrm{~mL}$ of $\mathrm{CaCl}_{2} .2 \mathrm{H}_{2} \mathrm{O}\left(0.01 \mathrm{~mol} \mathrm{~L}^{-1}\right)$ solution containing different quantities of cadmium $(0.10,1.80,19.00,46.60$ and $\left.105.70 \mathrm{mg} \mathrm{L}^{-1}\right)$. In the trial of the transport of $\mathrm{Cd}$ in soil columns a displacement solution of $105.70 \mathrm{mg} \mathrm{L}^{-1}$ was used. Sorption of $\mathrm{Cd}$ was evaluated by potential and linear models of the Freundlich isotherm and the retardation factor $(\mathrm{R})$ and hydrodynamic dispersion coefficient (D) were adjusted by minimizing the sum of squares of deviations between the experimental and simulated breakthrough curve. Both isothermal and linear potential and the adjustment of the transport parameters $D$ and $R$ showed a good fit for describing the adsorption and the displacement of $C d$ in the different studied soils. The Q uartzarenic N eosol showed lower retention of $\mathrm{Cd}$ in comparison to other classes of soil, and therefore more vulnerable to contamination of groundwater, followed by the Latosol, Argisol and Nitosol.
\end{abstract}

Key words: sorption isotherm, retardation factor, miscible displacement, hydrodynamics dispersion

\footnotetext{
1 UFLA, Bolsista em Produtividade do CN Pq, Departamento de Engenharia da UFLA, CP 3037, CEP 37200-000, Lavras, M G. Fone: (35) 3829-1679. E-mail: coutinho@deg.ufla.br

2 UFG. Rodovia Goiânia/N ova Veneza, km 0, CEP 74001-970, Goiânia, GO. Fone: (62) 3521-1542. E-mail: maralemke@uol.com.br; crissolocia@yahoo.com.br; jacomob@agro.ufg.br
} 


\section{INTRODUÇÃO}

A intensificação do uso das terras para fins agrícolas tem causado grande preocupação em virtude dos impactos ao meio ambiente, sobretudo no que diz respeito à sua contaminação por substâncias químicas. A disposição inadequada dos resíduos no solo sem um controle das doses e da forma de aplicação sem o conhecimento da capacidade de sua assimilação pelos diferentes tipos de solos predispõe, sem dúvida, a ocorrência de contaminação e de poluição ao longo do perfil desses solos podendo atingir o lençol freático e contaminar as águas subterrâneas (Oliveira, 1999).

Segundo Dias et al. (2001) o cádmio é considerado metal pesado amplamente utilizado para revestimento de materiais, pigmento de tintas e na indústria plástica, podendo ser adicionado ao solo por meio do lixo urbano ou industrial, lodo de esgoto e fertilizantes fosfatados; além disso, é facilmente absorvido e translocado nas plantas tendo potencial de entrar na cadeia alimentar humana, causando sérios problemas de saúde.

A mobilidade e a permanência dos solutos no solo e na água representam sérios impasses ambientais. Lima (2004) comenta que o movimento e o destino dos solutos no solo são influenciados pelos processos de transporte, retenção, transformação/degradação, volatilização e extração pelas plantas. Em razão da heterogeneidade dos constituintes do solo, esses processos são mecanismos complexos e suas interações no tempo e no espaço determinam o destino dos solutos no ambiente.

O solo possui grande capacidade de retenção dos metais pesados porém se esta capacidade for ultrapassada os metais alterarão sua disponibilidade para o meio. Devido às alterações do pH o solo interage, alterando sua capacidade de troca catiônica, modificando a estrutura cristalina dos grãos e criando condições que facilitam a lixiviação. Desta forma, os metais pesados penetram na cadeia alimentar dos organismos vivos ou podem ser lixiviados, pondo em risco a qualidade dos sistemas aquáticos adjacentes e as águas subterrâneas (Pierangeli et al., 2004; 2005; Campos et al., 2007).

A persistência e a mobilidade do soluto no solo são determinadas pela extensão de adsorção pelos colóides do solo. Os atributos do solo que mais influenciam a capacidade de adsorção de cádmio no solo são os teores de matéria orgânica e de óxidos de $\mathrm{Fe}$ e $\mathrm{Al}$, a capacidade de troca de cátions, o pH, a força iônica da solução, a superfície específica e a mineralogia (King, 1988; Gray et al., 1998).

A adsorção é o processo segundo o qual o soluto adere às superfícies das partículas do solo, especialmente dos argilominerais e da matéria orgânica, devido a forças de atração decorrentes de cargas desequilibradas nas superfícies dessas partículas, resultantes de imperfeições ou substituições iônicas na estrutura cristalina dos minerais (substituição isomorfa) ou de quebra de ligações nas estruturas moleculares, especialmente nas extremidades (Freeze \& Cherry, 1979).

Em geral, a quantidade de soluto adsorvida pelo solo é uma função da sua concentração na solução (D'Agostinho \& Flues, 2006; Falone \& Vieira, 2004). As isotermas de sorção são equações matemáticas que descrevem as relações entre a quantidade de determinado elemento químico adsorvido e sua quantidade remanescente na solução de equilíbrio. As equações de Langmuir e Freundlich têm sido utilizadas com frequência para descrever a adsorção de diferentes elementos químicos pela fase coloidal do solo (Dias et al., 2001).

A mobilidade de solutos no solo está inversamente relacionada à sua adsorção à fração sólida ou às condições do meio que favoreçam a precipitação dos íons. A adsorção iônica ao complexo de troca do solo faz com que os íons mantenham intercâmbio com a solução do solo, proporcionando ora sua retenção junto à fração sólida ora sua disponibilização no meio aquoso (Matos et al., 1998). Segundo Pierangeli et al. (2009) o aumento na imobilização de metais decorrente de maior sorção à superfície das partículas do solo é desejável, por ser uma forma de reduzir a mobilidade dos mesmos no perfil do solo e os impactos ambientais.

Lima \& Guilherme (2001) destacam que o níquel e o chumbo possuem baixa mobilidade no solo enquanto o cádmio e o cobre possuem mobilidade baixa a moderada; o cromo pode apresentar mobilidade baixa, moderada e alta e o zinco, mobilidade no solo variando de baixa a alta. Dias et al. (2001) verificaram que, para altas concentrações de cádmio, o Nitossolo Vermelho eutroférrico apresentou maiores valores de adsorção avaliada pela isoterma de Langmuir e, para menores concentrações, uma retenção maior nos horizontes subsuperficiais dos Latossolos.

Segundo Costa (2002), uma das formas de se expressar a capacidade de retenção do solo é o fator de retardamento, que é uma característica própria de determinado solo em relação a uma substância haja vista que inclui os processos de adsorção e precipitação e pode variar de acordo com alguns fatores, como a atividade do solo, concentração inicial da substância na solução, concentração de outras substâncias presentes na solução, pH da solução, temperatura e velocidade de percolação, entre outros.

Os processos pelos quais os poluentes são transportados nos solos são: advecção, dispersão mecânica e difusão molecular. Esses processos dependem de características locais, tais como condutividade hidráulica e umidade do solo, capacidade de troca catiônica do solo, $\mathrm{pH}$, granulometria, estrutura e grau de estratificação do perfil do solo. A pluma de contaminação sofre uma atenuação com o tempo e a distância pelos processos de absorção, trocas iônicas, dispersão e decaimento (Oliveira et al., 1999; Nascimento et al., 2006; Lukiantchuki, 2007).

O transporte por advecção caracteriza-se pela velocidade do fluxo hidráulico, ou seja, o contaminante é transportado junto com a massa de água acompanhando o fluxo subterrâneo natural. A difusão molecular é um processo espontâneo caracterizado por um espalhamento do material quando há diferença de concentração e predomina nos meios porosos nos quais a velocidade é mais lenta. A difusão pode, com o passar do tempo, atingir grandes distâncias, mesmo quando o meio poroso apresenta baixa permeabilidade. A dispersão mecânica ocorre no sentido do fluxo, como consequência das variações no fluxo entre os poros do solo e é caracterizada por um espalhamento do material (Reichardt \& Timm, 2004; Costa, 2002). 
Devido à similaridade entre a dispersão e a difusão, esses dois processos são tratados nos modelos matemáticos como aditivos, a cujo resultado se dá o nome de dispersão hidrodinâmica (Alves, 2008; Wallach et al., 1988).

A aplicação da teoria do deslocamento miscível em colunas de solo saturado, através da qual se faz passar uma solução deslocadora com concentração $\mathrm{C}_{0}$, permite a obtenção da curva de eluição, que expressa a concentração relativa $(\mathrm{C} /$ $\mathrm{C}_{\mathrm{o}}$ ) em função do número de volume de poros da solução coletada após passar pela coluna de solo (Reichardt \& Timm, 2004; Costa, 2002).

Empregando-se das soluções analíticas da equação de transporte, que são soluções particulares da mesma aos pontos da curva de eluição, é possível a estimativa, pelo método dos mínimos quadrados, do coeficiente de dispersão hidrodinâmica e do fator de retardamento; para tal, faz-se necessário a caracterização físico-hídrica do solo empregado no estudo. Esses parâmetros da equação do transporte, juntamente com a caracterização da retenção do solo, expressa pela isoterma de sorção, bem como o conhecimento da capacidade de troca catiônica do solo, permitem prever e simular a lixiviação do soluto no solo e a provável contaminação das águas subterrâneas (Maciel Netto, 2005; Lange et al., 2002; Costa, 2002).

Portanto, este trabalho tem, como objetivo, analisar o comportamento, no que refere ao transporte e retenção do cádmio em algumas classes de solo agricultáveis do Estado de Goiás. Os resultados obtidos permitiram verificar, dentre as classes de solos avaliadas, a propensão à lixiviação e contaminação do solo e das águas subterrâneas pelo cádmio.

\section{MATERIAL E MÉTODOS}

Considerando-se a predominância em áreas agricultáveis do Estado de Goiás selecionaram-se, para os estudos de sorção e mobilidade do cádmio, as seguintes classes de solo: Latossolo Vermelho Acriférrico (LVwf) da região de Jataí; Argissolo Vermelho Eutrófico (PVe) da região de Goiânia, Nitossolo Vermelho Eutroférrico (NVef) da região de Ouro Verde e Neossolo Quartzarênico (RQ) da região de Caçú/ Serranópolis.

Realizaram-se, para cada classe de solo, as amostragens do horizonte diagnóstico subsuperficial para as caracterizações físicas e químicas, segundo as metodologias preconizadas pela EMBRAPA (1999). Preferiu-se trabalhar com o horizonte subsuperficial pelo fato de que, neste horizonte, ocorrem os maiores gradientes texturais e estruturais que afetam diretamente os mecanismos de sorção e o movimento de água o qual está diretamente ligado ao transporte de solutos no solo. As análises físicas e químicas das classes de solo estudadas foram realizadas nos Laboratórios da Escola de Agronomia e Engenharia de Alimentos da Universidade Federal de Goiás, do Centro da Embrapa-Arroz e Feijão e da Empresa SoloCria.

Como análise complementar para se avaliar o tipo de argilomineral presente nas classes de solos estudadas, as amostras foram submetidas ao difratômetro de raios-X, no Labo- ratório de Mecânica das Rochas da Divisão de Geotecnia de FURNAS, localizado em Aparecida de Goiânia.

Os resultados das análises foram utilizados na análise da movimentação e retenção de água no solo, importantes no entendimento da dinâmica do transporte dos metais no solo e das análises químicas como suporte complementar, no que se refere à compreensão da retenção dos metais pelo solo, na análise do fator de retardamento e do coeficiente de dispersão hidrodinâmica.

Inicialmente, as amostras dos solos estudados foram destorroadas e passadas em uma peneira de 2,0 mm e, posteriormente, secadas à sombra, por um período, até que a umidade apresentasse pequena variação obtendo-se, assim, as amostras de terra fina secadas ao ar (TFSA).

Para o estabelecimento das isotermas de sorção puseramse, em um béquer, $5 \mathrm{~mL}$ de TFSA e, posteriormente, $50 \mathrm{~mL}$ de solução de $\mathrm{Cd}$ foram adicionados. As concentrações empregadas no estudo de sorção foram de 0,$10 ; 1,80 ; 19,00$; 46,60 e 105,70 $\mathrm{mg} \mathrm{L}^{-1}$, preparadas com cloreto de cádmio em $\mathrm{CaCl}_{2} 2 \mathrm{H}_{2} \mathrm{O}\left(0,01 \mathrm{~mol} \mathrm{~L}^{-1}\right)$ como eletrólito-suporte segundo recomendação de Chaves et al. (2008) e Correia et al. (2007). Com a finalidade de se aumentar o contato da solução com o solo, fez-se a homogeneização em uma mesa agitadora, durante de 24 h, segundo recomendação de Mellis \& Rodella (2008). Após a agitação as amostras foram acondicionadas em uma caixa de isopor e mantidas pelo tempo de $24 \mathrm{~h}$, para então se obter a concentração de equilíbrio, conforme descrito por Alves (2008); Correia et al. (2007) Arantes et al. (2006) e Jordão et al. (2000). A temperatura no interior da caixa foi monitorada com o auxílio de um termômetro para caixa de vacina.

Após o equilíbrio fez-se a filtragem da solução e as amostras do sobrenadante foram transferidas para frascos de vidro âmbar e armazenadas em um frezer, até o momento da determinação da concentração do cádmio em solução, pela técnica da espectrometria de absorção atômica. A concentração do metal adsorvido ao solo foi obtida pelo emprego da Eq. 1 .

$$
C_{s}=\left(C_{i}-C_{f}\right) \frac{V o l}{m}
$$

em que:

$\mathrm{C}_{\mathrm{s}}$ - concentração do metal adsorvido ao solo, $\mathrm{mg} \mathrm{kg}^{-1}$

$\mathrm{C}_{\mathrm{i}}$ e $\mathrm{C}_{\mathrm{f}}$ - concentrações inicial e final da solução, $\mathrm{mg} \mathrm{L}^{-1}$ $\mathrm{m}$ - massa da TFSA adicionada ao béquer, $\mathrm{kg}$

Vol - volume da solução adicionada ao béquer, L

Determinaram-se, para as diferentes classes de solo, as concentrações adsorvidas para cada valor de $\mathrm{C}_{\mathrm{i}}$, permitindo, assim, o ajuste das isotermas de sorção de Freundlich pelos modelos potenciais e lineares (Eq. 2). De posse do coeficiente angular da isoterma de sorção linear, $\left(\mathrm{K}_{\mathrm{d}}\right)$, determinouse o respectivo fator de retardamento, pelo emprego da Eq. 3.

$$
\begin{gathered}
\mathrm{C}_{\mathrm{s}}=\mathrm{K}_{\mathrm{f}} \mathrm{C}_{\mathrm{w}}^{\mathrm{N}} \text { e } \mathrm{C}_{\mathrm{s}}=\mathrm{K}_{\mathrm{d}} \mathrm{C}_{\mathrm{w}} \\
\mathrm{R}=1+\frac{\mathrm{D}_{\mathrm{s}}}{\mathrm{P}} \mathrm{K}_{\mathrm{d}}
\end{gathered}
$$


em que:

$\mathrm{C}_{\mathrm{w}}$ - concentração do soluto em solução, $\mathrm{mg} \mathrm{m}^{-3}$

$\mathrm{K}_{\mathrm{f}} \mathrm{e} \mathrm{N}$ - coeficiente e expoente da isoterma de Freundlich

$\mathrm{K}_{\mathrm{d}}$ - coeficiente de distribuição linear, $\mathrm{m}^{3} \mathrm{~kg}^{-1}$

$\mathrm{P}$ - porosidade total do solo, $\mathrm{m}^{3} \mathrm{~m}^{-3}$

$\mathrm{D}_{\mathrm{s}}$ - massa específica do solo, $\mathrm{kg} \mathrm{m}^{-3}$

Para determinação das curvas de eluição, da condutividade hidráulica e do fluxo de água do solo saturado, empregaram-se segmentos de tubo PVC com 0,20 m de altura e 0,05 m de diâmetro. O segmento de tubo de PVC foi cravado no solo por percussão e após seu preenchimento foi devidamente embalado com gaze no topo e na base da coluna, depois envolvido com filme de PVC; posteriormente, as colunas foram inseridas em tubos de papelão e encaminhadas ao laboratório, no qual as colunas de solos foram colocadas para saturar, de tal forma que $2 / 3$ da altura da coluna ficassem submersos com o objetivo de se expulsar o ar presente nos poros do solo. As colunas foram saturadas com solução iônica de $\mathrm{CaCl}_{2} 2 \mathrm{H}_{2} \mathrm{O}$ $\left(0,01 \mathrm{~mol} \mathrm{~L}^{-1}\right)$, próxima à da solução do solo, para que os colóides do solo não sofressem desestabilização comprometendo a permeabilidade devido à diminuição da força iônica (Milfont et al., 2006). Após a saturação as colunas de solo foram montadas em um permeâmetro de carga constante e, pelo tempo de $24 \mathrm{~h}$, se manteve no topo da coluna uma carga hidráulica de $0,2 \mathrm{~m}$, com solução iônica de $\mathrm{CaCl}_{2} 2 \mathrm{H}_{2} \mathrm{O}$ $\left(0,01 \mathrm{~mol} \mathrm{~L}^{-1}\right)$, para se promover a lixiviação do solo; posteriormente se aplicou uma solução deslocadora de cádmio na concentração de $105,70 \mathrm{mg} \mathrm{L}^{-1}$ e a coleta das alíquotas da solução efluente, correspondente a $10 \mathrm{~mL}$, foi realizada com o auxílio de uma proveta graduada. Amostras da solução efluente foram coletadas até que a concentração se aproximasse da solução deslocadora, conforme descrito por Genuchten \& Wierenga (1986) e Oliveira et al. (1999). As alíquotas das soluções efluentes foram transferidas para frascos de vidro âmbar e armazenadas em um frezer até o momento da determinação da concentração do cádmio em solução, pela técnica da espectrometria de absorção atômica.

O fluxo e a velocidade média de escoamento de água no solo, a condutividade hidráulica do solo saturado e a coleta das alíquotas da solução efluente para a construção da curva de eluição, foram determinados simultaneamente, segundo a metodologia descrita por Oliveira et al. (1999; 2000).

Para o traçado da curva de eluição experimental os volumes das alíquotas dos efluentes foram acumulados e adimensionalizados pelo volume total de poros do solo e as concentrações de cada alíquota, pela concentração inicial da solução deslocadora $\left(\mathrm{C}_{\mathrm{o}}\right)$. Utilizando-se uma planilha eletrônica, ajustaram-se os valores dos fatores de retardamento $(\mathrm{R})$ e dos coeficientes de dispersão hidrodinâmica (D); nesta planilha, foi modelada a solução analítica da equação de transporte apresentada por Genuchten \& Wierenga (1986) (Eq. 4), em que, inicialmente, se atribuíram valores a $\mathrm{R}$ e $\mathrm{D}$ e a solução do ajuste foi obtida com a rotina Solver, de modo a minimizar a soma dos quadrados dos desvios entre a curva de eluição experimental e a simulada.

$\frac{C}{C_{0}}=\frac{1}{2}\left[\operatorname{erfc}\left(\frac{R x-v t}{\sqrt{4 D R t}}\right)-\left(1+\frac{v x}{D}+\frac{v^{2} t}{D R}\right) e^{(v \times D)} \operatorname{erfc}\left(\frac{R x+v t}{\sqrt{4 D R t}}\right)\right]+\sqrt{\frac{v^{2} t}{\pi D R}} e^{\left.-\frac{\left(R x-v t^{2}\right.}{4 D R t}\right]}$ em que:

C - concentração do soluto na solução efluente, $m g \mathrm{~L}^{-1}$

$\mathrm{C}_{\mathrm{o}}$ - concentração da solução deslocadora, mg L $\mathrm{L}^{-1}$

$\mathrm{R}$ - fator de retardamento

$\mathrm{x}$ - comprimento da coluna de solo, $\mathrm{m}$

$\mathrm{t}$ - tempo, $\mathrm{s}$

$\mathrm{D}$ - coeficiente de dispersão, $\mathrm{m}^{2} \mathrm{~s}^{-1}$

$\mathrm{v}$ - velocidade média da solução na coluna de solo, $\mathrm{m} \mathrm{s}^{-1}$

erfc - função erro complementar

No desenvolvimento da planilha utilizou-se, para o cálculo da função erro complementar, a aproximação apresentada por Oliveira et al. (1999), dada por:

$$
\operatorname{erfc}(x)=\frac{1}{\left(1+a_{1} x+a_{2} x^{2}+\ldots+a_{6} x^{6}\right)^{16}}
$$

em que:

$$
\begin{aligned}
& \mathrm{a}_{1}=0,0705230784 \\
& \mathrm{a}_{2}=0,0422820123 \\
& \mathrm{a}_{3}=0,0092705272 \\
& \mathrm{a}_{4}=0,0001520143 \\
& \mathrm{a}_{5}=0,0002765672 \\
& \mathrm{a}_{6}=0,0000430638
\end{aligned}
$$

As isotermas de sorção, bem como os fatores de retardamento (R) e os coeficientes de dispersão hidrodinâmica (D), foram avaliados para se verificar qual a potencialidade de cada solo no que se refere à retenção, à mobilidade e à potencialidade de contaminação do cádmio, principalmente de águas subterrâneas, para as diferentes classes de solos.

\section{RESULTADOS E DISCUSSÃO}

A Tabela 1 apresenta os resultados das análises físicas dos solos utilizados nos ensaios de sorção e mobilidade de metais. Observa-se alta porcentagem da fração argila acima de 70\% para o PVe, LVwf e NVef, diferente do RQ, que indica uma grande porcentagem da fração areia. Pelos resultados da condutividade hidráulica do solo saturado obtidos no permeâmetro de carga constante, o PVe e o NVef apresentaram baixa taxa de fluxo de água e, consequentemente, baixa condutividade hidráulica, que os classificam lentos com relação à movimentação de água no solo, comportamento que se deve, sobretudo, à forte estruturação em blocos dessas classes de solo, reduzindo a macroporosidade e a movimentação de água. Por outro lado, o RQ e o LVwf foram classificados em moderadamente rápido e moderado com relação à movimentação de água, respectivamente. Esses tipos de solo apresentam uma quantidade maior de macroporos em relação ao PVe e ao NVef devido à estruturação granular, o que favorece o fluxo de água no solo

Pelas análises químicas das classes de solo empregadas neste estudo sugere-se, segundo a EMBRAPA (2006), que o PVe e o NVef são cauliníticos com boa retenção de cátions $\left(8,61<\mathrm{T}<15, \mathrm{~K}_{\mathrm{i}}\right.$ e $\left.\mathrm{K}_{\mathrm{r}}>0,75\right)$ e o LVwf e o RQ são solos gibbsíticos/oxídicos que possuem baixa capacidade de reten- 
ção de cátions $\left(1,61<\mathrm{T}<4,3, \mathrm{~K}_{\mathrm{i}}\right.$ e $\left.\mathrm{K}_{\mathrm{r}} \leq 0,75\right)$ (Tabela 2). Observa-se, na Tabela 2, que o pH do PVe, RQ e o NVef, apresentam acidez fraca a neutra porém no LVwf esta acidez, sinaliza predominância de cargas positivas.

A mineralogia dos argilominerais presentes no Argissolo (PVe) e do Nitossolo (NVef) identificadas nos difratogramas de raios-X tem, como principal mineral secundário, a caulinita seguida da gibbsita e hematita, no caso NVef e de ilita e magnetita no caso do PVe; já para o Latossolo (LVwf) observou-se mineralogia predominantemente oxídica. As análises nos difratogramas de raios-X concordam com os resultados obtidos para os índices de intemperismo $\mathrm{K}_{\mathrm{i}}$ e $\mathrm{K}_{\mathrm{r}}$. Em relação ao Neossolo Quartzarênico (RQ), não foi realizada a análise mineralógica no difratômetro de raios-X, em razão do baixo porcentual da fração argila encontrado neste solo e por apresentar valores de $\mathrm{K}_{\mathrm{i}}$ e $\mathrm{K}_{\mathrm{r}} \leq 0,75$ conferindo, a esta classe de solo, predominância oxídica.

Tabela 1. Atributos físicos utilizados nos ensaios de sorção e deslocamento do cádmio para as diferentes classes de solo

\begin{tabular}{|c|c|c|c|c|c|c|c|}
\hline \multirow[t]{2}{*}{ Solo* } & \multirow{2}{*}{$\begin{array}{c}D_{s} \\
\mathrm{~kg} \mathrm{dm}^{-3}\end{array}$} & \multirow{2}{*}{$\underset{\mathbf{m}^{3} \mathbf{m}^{-3}}{\mathbf{P}}$} & Areia & Silte & Argila & \multirow{2}{*}{$\underset{\mathrm{m}}{\mathrm{K}_{\mathrm{o}}} \mathrm{d}^{-1}$} & \multirow[t]{2}{*}{ Classe } \\
\hline & & & & $\%$ & & & \\
\hline PVe & 1,20 & 0,55 & 12,7 & 11,2 & 76,1 & 0,09 & Lenta \\
\hline LVwf & 1,09 & 0,56 & 11,8 & 17,8 & 70,4 & 1,35 & Moderada \\
\hline $\mathrm{RQ}$ & 1,10 & 0,58 & 79,0 & 6,0 & 15,0 & 1,64 & Mod. rápida \\
\hline NVef & 1,30 & 0,49 & 7,5 & 13,6 & 78,9 & 0,08 & Lenta \\
\hline
\end{tabular}

* LVwf - Latossolo Vermelho Acriferrico; PVe - Argissol Vermelho Eutrófico; NVef - Nitossolo Vermelho Eutroférrico; RQ - Neossolo Quartzarênico

$D_{s}$ - massa específica do solo, $P$ - porosidade total e $K_{0}$ - condutividade hidráulica

Tabela 2. A tributos químicos das classes de solos utilizados nos ensaios de sorção e deslocamento do cádmio

\begin{tabular}{|c|c|c|c|c|c|c|c|}
\hline \multirow{2}{*}{ Solo* } & $S$ & $T$ & \multirow{2}{*}{$\begin{array}{c}V \\
(\%)\end{array}$} & \multirow{2}{*}{$\mathrm{pH}$} & \multirow{2}{*}{$\begin{array}{c}\mathrm{CO} \\
\left(\mathrm{g} \mathrm{kg}^{-1}\right)\end{array}$} & \multirow{2}{*}{$K_{i}$} & \multirow{2}{*}{$\mathrm{K}_{\mathrm{r}}$} \\
\hline & \multicolumn{2}{|c|}{$\left(\mathrm{cmol}_{\mathrm{c}} \mathrm{dm}^{-3}\right)$} & & & & & \\
\hline PVe & 8,53 & 11,43 & 74,64 & 6,60 & 4,10 & 1,55 & 1,02 \\
\hline LVwf & 0,35 & 3,65 & 9,59 & 3,80 & 7,00 & 0,68 & 0,40 \\
\hline RQ & 1,44 & 3,43 & 41,96 & 6,54 & 0,82 & 0,74 & 0,45 \\
\hline NVef & 7,27 & 9,27 & 78,43 & 6,00 & 4,00 & 1,73 & 1,17 \\
\hline
\end{tabular}

* LVwf - Latossolo Vermelho Acriferrico; PVe - Argissol Vermelho Eutrófico; NVef - Nitossolo Vermelho Eutroférrico; RQ - Neossolo Quartzarênico

$\mathrm{S}$ - soma de bases, T - capacidade de troca catiônica, V - saturação por bases, CO - carbono orgânico, $\mathrm{K}_{\mathrm{i}}$ e $\mathrm{K}_{\mathrm{r}}$ - índices de intemperismo

A Tabela 3 apresenta os parâmetros ajustados das isotermas de sorção linear e potencial do cádmio para as diferentes classes de solo avaliadas em uma faixa de temperatura de $26 \pm 2{ }^{\circ} \mathrm{C}$ e do fator de retardamento, obtidos pelo emprego da Eq. 3. De modo geral, as isotermas potenciais apresentaram melhor ajuste quando comparadas com a linear, com coeficientes de determinação $\left(R^{2}\right)$ acima 0,75 . O comportamento das isotermas ajustadas aos pontos amostrais pode ser visualizado na Figura 1.

Em geral, o RQ possui menor capacidade de retenção do cádmio (menores valores de $\mathrm{K}_{\mathrm{d}} \mathrm{e} \mathrm{R}$ ). $\mathrm{O}$ que, associado à movimentação de água nesta classe de solo, oferece um risco maior de contaminação das águas subterrâneas. A baixa retenção do $\mathrm{Cd}$ nesta classe de solo está associada à baixa porcentagem da fração argila, responsável pelos sítios de troca (baixa CTC) e pelo tipo de argilomineral encontrado (pre-
Tabela 3. Isotermas de sorção linear e potencial e fator de retardamento (R) para cádmio

\begin{tabular}{cccccccc}
\hline \multirow{2}{*}{ Solo* } & \multicolumn{2}{c}{ Linear } & & \multicolumn{3}{c}{ Potencial } & \multirow{2}{*}{$\mathbf{R}$} \\
\cline { 2 - 3 } \cline { 5 - 6 } & $\mathbf{K}_{\mathbf{d}}$ & $\mathbf{r}^{\mathbf{2}}$ & & $\mathbf{K}_{\mathbf{f}}$ & $\mathbf{N}$ & $\mathbf{r}^{2}$ & \\
PVe & 0,7115 & 0,9031 & & 2,3359 & 0,7605 & 0,9559 & 2,55 \\
LVwf & 1,7831 & 0,9906 & & 2,9897 & 0,8671 & 0,9706 & 4,47 \\
RQ & 0,5113 & 0,9745 & & 1,7942 & 0,7117 & 0,9345 & 2,46 \\
NVef & 0,4304 & 0,8566 & & 1,1587 & 0,5947 & 0,7603 & 2,14 \\
\hline
\end{tabular}

* LVwf - Latossolo Vermelho Acriferrico; PVe - Argissol Vermelho Eutrófico; NVef - Nitossolo Vermelho Eutroférrico; RQ - Neossolo Quartzarênico

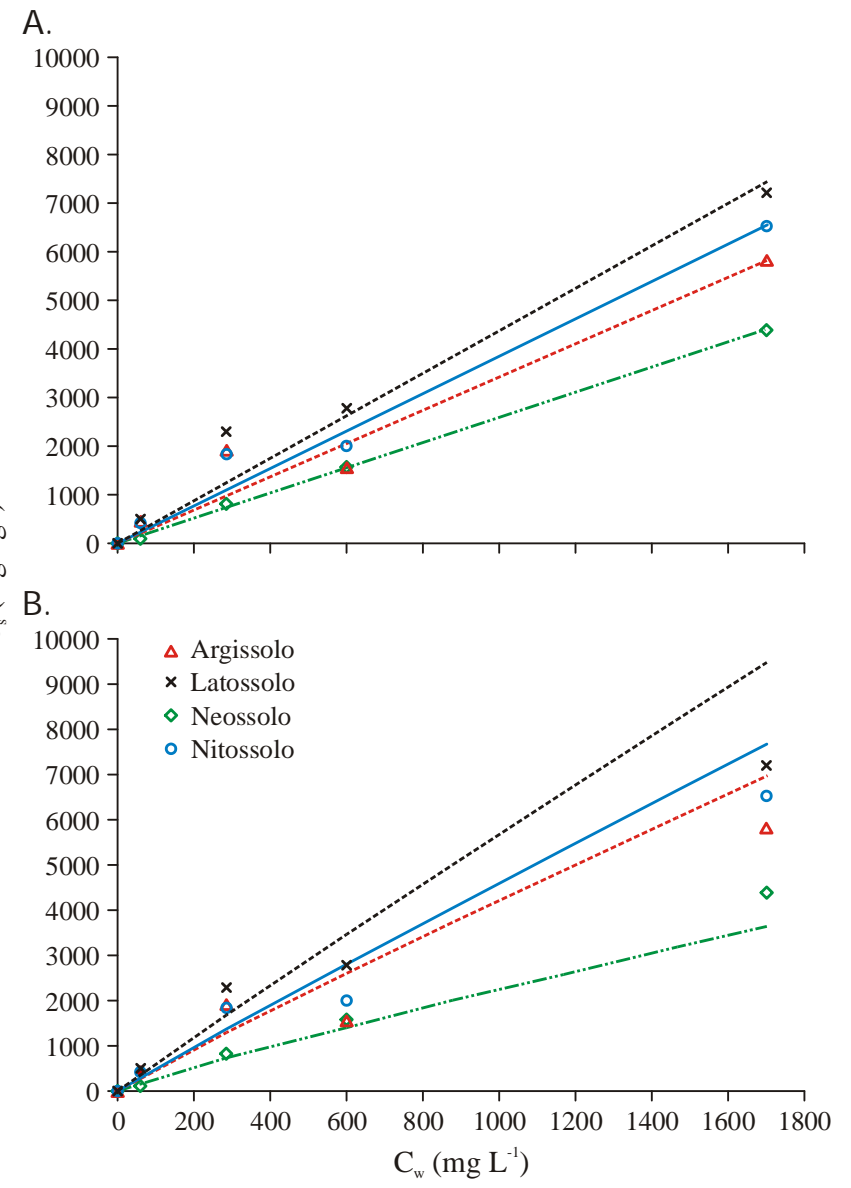

Figura 1. Isotermas de sorcão linear $(A)$ e potencial $(B)$ para o cádmio no Argissolo (PVe), Latossolo (LVwf), N eossolo Q uartzarênico (RQ) e N itossolo (NVef)

domínio de óxidos), concordando com Souza et al. (2006); Dias et al. (2001) e Sodré et al. (2001). Por outro lado, nos solos com maiores concentrações de argila, principalmente da caulinita (PVe e NVef), observa-se uma propensão no que se refere à sorção do cádmio pois, segundo Pierangeli et al. (2007) a retenção de Cd ocorre, na sua maior parte, por meio das forças eletrostáticas das partículas negativamente carregadas, o que a torna bastante dependente da CTC dos solos.

Para o LVwf, se apesar da predominância de um $\mathrm{pH}$ ácido, verificaram-se os maiores valores de $K_{d}$ e $R$ em virtude da alta concentração de matéria orgânica e óxidos de ferro (25,50\% do total dos óxidos) observados para esta classe de solo, cujo comportamento concorda com Costa et al. (2007) na avaliação do fracionamento sequencial do $\mathrm{Cd}$, constatando-se que este metal também foi bastante retido nas frações 
orgânicas e residuais nas classes de solo estudadas indicando que, em condições de baixa competição com outros cátions, apresenta tendência de permanecer sob formas menos disponíveis e adsorvido especificamente na matéria orgânica, nos minerais silicatados e nos óxidos. Os autores verificaram, também, a forte afinidade do $\mathrm{Cd}$ pelos óxidos de ferro (hematita) constituintes dos Latossolos.

A Tabela 4 apresenta os valores do fator de retardamento (R) e do coeficiente de dispersão hidrodinâmica, obtidos nos ensaios do deslocamento do Cd nas colunas de solo. De modo geral, os referidos parâmetros apresentaram bom ajuste à solução analítica, proposta por Genuchten \& Wierenga (1986), com coeficientes de determinação $\left(\mathrm{R}^{2}\right)$ acima de 0,85 (Figura 2).

Tabela 4. Fator de retardamento $(R)$ e do coeficiente de dispersão hidrodinâmica (D) para o cádmio para as diferentes classes de solo

\begin{tabular}{cccc}
\hline Solo* & $\mathbf{R}$ & $\mathbf{D}\left(\mathbf{c m}^{\mathbf{2}} \mathbf{h}^{-1}\right)$ & $\mathbf{r}^{\mathbf{2}}$ \\
PVe & 2,77 & 27,53 & 0,9859 \\
LVwf & 1,35 & 35,48 & 0,8594 \\
RQ & 0,98 & 52,25 & 0,9672 \\
NVef & 3,34 & 19,53 & 0,9889 \\
\hline
\end{tabular}

* LVwf - Latossolo Vermelho Acriferrico; PVe - Argissol Vermelho Eutrófico; NVef - Nitossolo Vermelho Eutroférrico; RQ - Neossolo Quartzarênico

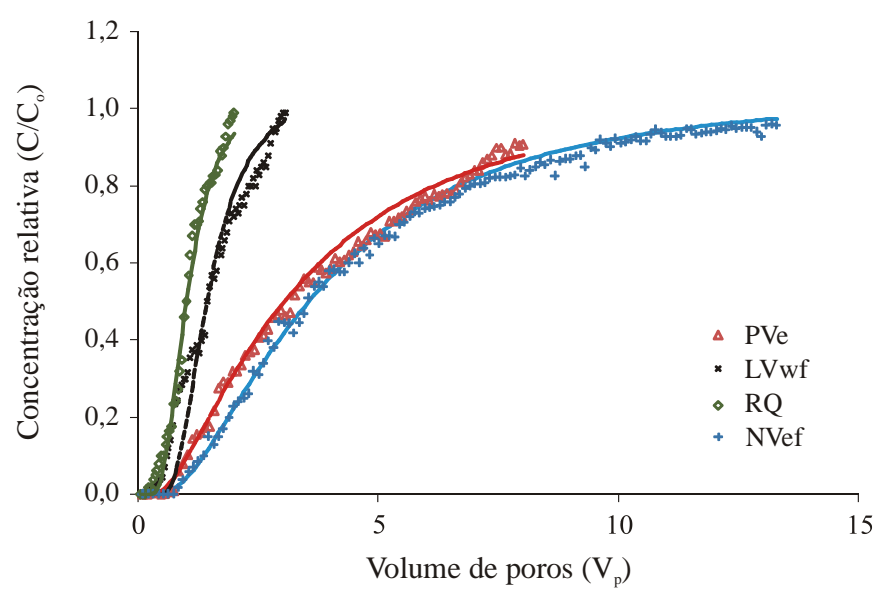

Figura 2. Curvas de eluição experimentais e simuladas do cádmio para 0 Argissolo (PVe), Latossolo (LVwf), N eossolo Q uartzarênico (RQ) e Nitossolo (NVef)

Observa-se, pela Tabela 4, que para os PVe e NVef os valores dos fatores de retardamento ajustados se aproximaram dos calculados com base no coeficiente de partição das isotermas lineares (Tabela 3). Nessas duas classes de solo se observou um fluxo lento da solução pelo espaço poroso do solo em virtude, principalmente, do tipo de estrutura em blocos característicos desses solos, que proporcionou maior tempo de contato do Cd favorecendo, assim, sua adsorção. Por fim, os valores de R ajustados pelo ensaio do deslocamento do Cd nas colunas do LVwf e RQ foram bem inferiores aos obtidos no ensaio de sorção, fato que pode ser atribuído ao maior fluxo da solução no espaço poroso dessas classes de solo o que, provavelmente, reduziu o tempo de contato do Cd com os sítios de troca de carga, reduzindo a adsorção e favorecendo o seu deslocamento. No ensaio de sorção, como a solução contendo o Cd ficou em repouso por $24 \mathrm{~h}$, ocorreu um tempo maior de contato, o que pode aumentar a adsorção deste elemento.

Os valores dos coeficientes de dispersão hidrodinâmica encontrados nos ensaios do deslocamento do cádmio reforçam a discussão do ensaio de sorção, em que os metais que foram mais fortemente adsorvidos pelo solo apresentam baixa mobilidade no solo, ou seja, quanto maior o fator de retardamento menor o coeficiente de dispersão hidrodinâmica (Tabela 4).

De modo geral, o Neossolo Quartzarênico (RQ) apresentou os maiores e menores valores de $\mathrm{D}$ e $\mathrm{R}$, respectiva e consequentemente, em virtude da mais alta taxa de movimentação de água no solo; em comparação com as demais classes de solo avaliadas, apresenta propensão maior à contaminação das águas subterrâneas pelo íon $\mathrm{Cd}$. $\mathrm{Na}$ sequência, se tem, com relação ao deslocamento do $\mathrm{Cd}$, em ordem decrescente, LVwf > PVe > NVef.

\section{CONCLUSÕES}

1. Tanto o modelo linear quanto o potencial das isotermas de Freundlich se adequaram bem aos valores de $\mathrm{Cd}$ adsorvido aos solos agricultáveis encontrados no cerrado do Estado de Goiás.

2. A solução analítica da equação de transporte que descreve o deslocamento miscível dos metais no solo, permitiu não só um bom ajuste das curvas de eluição mas também a obtenção do fator de retardamento e do coeficiente de dispersão hidrodinâmica.

3. De modo geral, o Neossolo Quartzarênico apresentou maior propensão ao deslocamento do cádmio no solo seguido dos Latossolo, Argissolo e Nitossolo.

\section{AGRADECIMENTOS}

Ao Conselho Nacional de Desenvolvimento Científico e Tecnológico $(\mathrm{CNPq})$, pelo aporte financeiro ao projeto de pesquisa "Retenção e transporte de metais pesados em solos agricultáveis do estado de Goiás".

\section{LITERATURA CITADA}

Alves, D. N. B. Remoção de ferro em água de irrigação através de filtragem em areia e zeólita. Lavras: UFLA, 2008. 97p. Tese Doutorado

Arantes, S. A. C. M.; Lima, J. M.; Nóbrega, J. C. A.; Guilherme L. R. G.; Julião, L. G. F.; Jesus, E. A. Sorção de atrazina em solos representativos da Sub-Bacia do Rio das Mortes, MG. Pesticidas: Revista de Ecotoxicologia e Meio Ambiente, v.16, p.101-110, 2006.

Campos, M. L.; Guilherme, L. R. G.; Lopes, R. S.; Antunes, A. S.; Marques, J. J. G. S. M.; Curi, N. Teor e capacidade máxima de adsorção de arsênio em latossolos brasileiros. Revista Brasileira de Ciência do Solo, v.31, p.1311-1318, 2007. 
Chaves, L. H. G.; Souza, R. S.; Tito, G. A. Adsorção de zinco em argissolos do estado da Paraíba: efeito do $\mathrm{pH}$. Revista Ciência Agronômica, v.39, n.4, p.511-516, 2008.

Correia, F. V.; Mercante, F. M.; Fabrício, A. C.; Campos, T. M. P.; Vargas Junior, E.; Langenbach, T. Adsorção de atrazina em solo tropical sob plantio direto e convencional. Pesticidas: Revista de Ecotoxicologia e Meio Ambiente, v.17, p.37-46, 2007.

Costa, C. N.; Meurer, E. J.; Bissani, C. A.; Tedesco, M. J. Fracionamento seqüencial de cádmio e chumbo em solos. Ciência Rural, v.37, n.5, p.1323-1328, 2007.

Costa, P. O. S. Avaliação em laboratório do transporte de contaminantes no solo do aterro sanitário de Sauípe, BA. Rio de Janeiro: PUC, 2002, 151p. Dissertação Mestrado

D’Agostinho, A.; Flues, M. Determinação do coeficiente de distribuição $(\mathrm{Kd})$ de benzo(a)pireno em solo por isotermas de sorção. Química Nova, v.29, n.4, p.657-661, 2006.

Dias, N. M. P.; Alleoni, L. R. F.; Casagrande, J. C.; Camargo, O. A. Isotermas de adsorção de cádmio em solos ácricos. Revista Brasileira de Engenharia Agrícola e Ambiental, v.5, n.2, p.229-234, 2001.

EMBRAPA - Empresa Brasileira de Pesquisa Agropecuária. Manual de análises químicas de solos, plantas e fertilizantes. Brasília: Embrapa Solos/Embrapa Informática Agropecuária/ Embrapa Comunicação para Transferência de Tecnologia, 1999. 370p.

EMBRAPA - Empresa Brasileira de Pesquisa Agropecuária. Centro Nacional de Pesquisa de Solos. Sistema brasileiro de classificação de solos. Brasília: Embrapa Produção de Informações; Rio de Janeiro: Embrapa Solos, 2006. 306p.

Falone, S. Z.; Vieira, E. M. Adsorção/dessorção do explosivo tetril em turfa e em argissolo vermelho amarelo. Química Nova, v.27, n.6, p.849-854, 2004.

Freeze, A.; Chery, J. A. Groundwater. Englewood Cliffs: Prentice-Hall, 1979. 604p.

Genuchten, M. T.; Wierenga, P. J. Solute dispersion coefficients and retardation factors. In: Klute, A. Methods of soil analysis: Part 1 - Physical and mineralogical methods. Madison: Soil Science Society of America, 1986. p.1025-1054.

Gray, C. W.; Mclaren, R. G.; Roberts, A. H. C.; Condron, L. M. Sorption de cadmium from some New Zealand soils: Effect of $\mathrm{pH}$ and contact time. Australian Journal of Soil Research, v.36, p.199-216, 1998.

Jordão, C. P.; Alves, N. M.; Pereira, J. L.; Bellato, C. R. Adsorção de íons $\mathrm{Cu}^{2+}$ em Latossolo Vermelho-Amarelo Húmico. Química Nova, v.23, n.1, p.5-11, 2000.

King, L. D. Retention of metals by several soils of the Southeastern United States. Journal of Environmental Quality, v.17, p.239-246, 1988.

Lange, L. C.; Simões, G. F.; Ferreira, C. F. A.; Coelho, H. M. G. Estudo do transporte de contaminantes em meios porosos Aplicado a aterros de disposição de resíduos sólidos urbanos. In: Castilhos Junior, A. B.; Lange, L. C.; Gomes, L. P.; Pessin, N. (ed.). Alternativas de disposição de resíduos sólidos urbanos para pequenas comunidades. Rio de Janeiro: RiMa, ABES, 2002. p.85-92.

Lima, D. M. Sorção e deslocamento miscível da antrazina em amostras de latossolos. Lavras: UFLA, 2004. 66p. Dissertação Mestrado
Lima, J. M.; Guilherme, L. R. G. Recursos naturais renováveis e impacto ambiental: Solo. In: Lima, J. M.; Guilherme, L. R. G.; Carvalho, M. S. (ed.). Recursos naturais renováveis e impacto ambiental. Lavras: UFLA/FAEPE, 2001. cap. 2, p.33-69.

Lukiantchuki, J. A. Influência do teor de bentonita na condutividade hidráulica e na resistência ao cisalhamento de um solo arenoso utilizado como barreira impermeabilizante. São Carlos: USP, 2007, 124p. Dissertação Mestrado

Maciel Netto, A. Instrumentação para caracterização hidrodispersiva em colunas de solo. In: Instrumentação para caracterização hidrodispersiva em colunas de solo, In: Congresso Brasileiro de Ciência do Solo, 30. Recife. Anais... Recife: SBCS, 2005. CD-Rom

Matos, A. T.; Costa, L. M.; Fontes, M. P. F.; Martinez, M. A. Correlação entre os fatores de retardamento e coeficientes de dispersão-difusão do zinco, cádmio, cobre e chumbo, e algumas propriedades físicas dos solos. Engenharia na Agricultura, v.6, n.4, p.235-246, 1998.

Mellis, E. V.; Rodella, A. A. Influência do tempo de agitação na adsorção de $\mathrm{Cd}, \mathrm{Cu}$, Ni e $\mathrm{Zn}$ em latossolo tratado com lodo de esgoto. Bragantia, v.67, n.4, p.977-982, 2008.

Milfont, M. L.; Antonino, A. C. D.; Martins, J. M. F.; Maciel Netto, A.; Corrêa, M. M. Caracterização hidrodispersiva de dois solos do Vale do Rio São Francisco. Revista Brasileira de Ciências Agrárias, v.1, n.único, p.81-87, 2006.

Nascimento, S. C.; Hypolito, R.; Ribeiro, A. A. Disponibilidade de metais pesados em aterro de indústria siderúrgica. Engenharia Sanitária e Ambiental, v.11, n.3, p.196-202, 2006.

Oliveira, L. F. C. Modelo para transporte de solutos no solo e no escoamento superficial. Viçosa: UFV, 1999. 171p. Tese Doutorado

Oliveira, L. F. C.; Carvalho, D. F.; Ferreira, P. A. Comparação de metodologias de determinação do coeficiente de dispersão para o cloreto de cálcio em um Latossolo Vermelho-Amarelo. Revista Brasileira de Engenharia Agrícola e Ambiental, v.3, n.1, p.7-10, 1999.

Oliveira, L. F. C.; Martinez, M. A.; Pruski, F. F.; Ruiz, H. A.; Matos, A. T. Metodologia de amostragem de solo para a obtenção da condutividade hidráulica do solo saturado e da curva de eluição de solutos. Engenharia na Agricultura, v.8, n.2, p.112-121, 2000.

Pierangeli, M. A. P.; Guilherme, L. R. G.; Curi, N.; Anderson, S. J.; Lima, J. M. Adsorção e dessorção de cádmio, cobre e chumbo por amostras de latossolos pré-tratadas com fósforo. Revista Brasileira de Ciência do Solo, v.28, n.2, p.377-384, 2004.

Pierangeli, M. A. P.; Guilherme, L. R. G.; Curi, N.; Costa, E. T. S.; Lima, J. M.; Marques, J. J. G. S. M.; Figueiredo, L. F. P. Comportamento sortivo, individual e competitivo, de metais pesados em Latossolos com mineralogia contrastante. Revista Brasileira de Ciência do Solo, v.31, p.819-826, 2007.

Pierangeli, M. A. P.; Guilherme, L. R. G.; Curi, N.; Silva, M. L. N.; Lima, J. M.; Costa, E. T. S. Efeito do pH na adsorção e dessorção de cádmio em Latossolos brasileiros. Revista Brasileira de Ciência do Solo, v.29, n. 4, p. 523-532, 2005.

Pierangeli, M. A. P.; Nóbrega, J. C. A.; Lima, J. M; Guilherme, L. R. G.; Arantes, S. A. C. M. Sorção de cádmio e chumbo em Latossolo Vermelho Distrófico sob efeito de calcário e fosfato. Revista Brasileira de Ciências Agrárias, v.4, n.1, p.42-47, 2009. 
Reichardt, K.; Timm, L. C. Solo, planta e atmosfera: Conceitos, processos e aplicações. São Paulo: Manole, 2004. 478p.

Sodré, F. F.; Lenzi E.; Costa, A. C. S. Utilização de modelos físico-químicos de adsorção no estudo do comportamento do cobre em solos argilosos. Química Nova, v.24, n.3, p.324-330, 2001.
Souza, R. S.; Chaves, L. H. G.; Fernandes, J. D. Adsorção de zinco e sua relação com características de solos do Estado da Paraíba. Revista Brasileira de Ciências Agrárias, v.1, n.único, p.1-6, 2006. Wallach, R.; Jury, W. A.; Spencer, W. F. Transfer of chemical from soil solution to surface runoff: A diffusion-based soil model. Soil Science Society of Amerca Journal, v.52, n.3, p.612-618, 1988. 